\title{
Endoscopic characterization of rectal neuroendocrine tumors with virtual chromoendoscopy: differences between benign and malignant lesions
}

Most rectal neuroendocrine tumors (rNETs) are small ( $\leq 20 \mathrm{~mm}$ ) and incidentally discovered at a localized stage during endoscopic procedures for unrelated indications [1]. Endoscopically, localized rNET, as presented here in a first example, is usually a small unique yellowish submucosal nodule, embedded in the rectal wall, with round shape pit pattern, type I on Kudo classification, and invisible vessels, as described by Sano as type I ( Fig. 1 a-c). Histologic analysis of such lesions shows them to be grade 1 of the World Health Organization (WHO) classification, without muscular or lymphovascular invasion; they have an excellent prognosis with negligible risk of local and distant recurrence ( $\triangleright$ Fig. 1 d) [1].

We report here a rare case of an invasive rNET in a 59-year-old patient that was resected by endoscopic submucosal dissection after multidisciplinary discussion in order to evaluate its invasion degree and its metastatic potential.

Its endoscopic appearance was different from localized rNETs, showing mucosal ulceration owing to a large smooth nodule, as previously described in gastric G2 NETs [2]. The size of the lesion was approximately $15 \mathrm{~mm}$. Narrow-band imaging (NBI) with dual-focus magnification showed an absence of pit pattern with large amorphous areas, what is described in Kudo's classification as a Vn pit pattern [3]. The vascular pattern was irregular, composed of meshed capillary vessels with blind ending, and some avascular areas, consistent with the type IIIb pattern of Sano's classification [4] ( Fig.2a-c). The tumor background appeared whitish between the large irregular vessels. Histologic analysis found grade 2 of the WHO classification (Ki67\% of $16.8 \%$ ), muscular involvement, with vascular and lymphatic invasion ( $\mathbf{F i g} \mathbf{2 d}$ ). The deep resection margin was invaded because of muscular invasion. A computed tomography (CT) scan

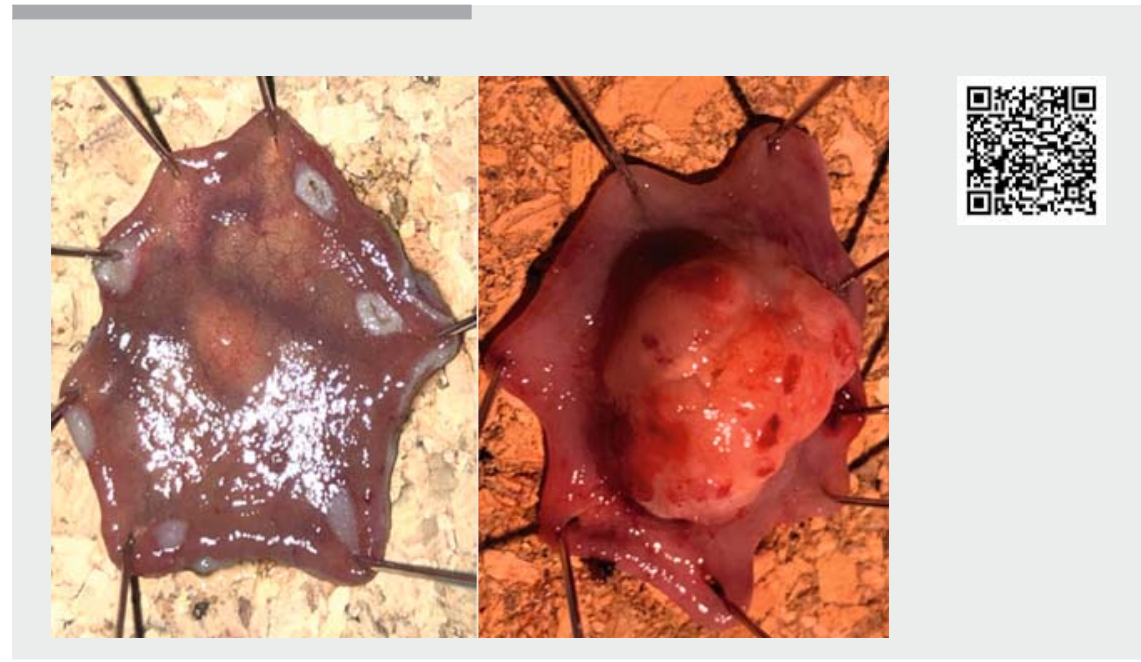

$\nabla$ Video 1 Endoscopic characterization of rectal neuroendocrine tumors with virtual chromoendoscopy showing the differences between benign and malignant lesions.
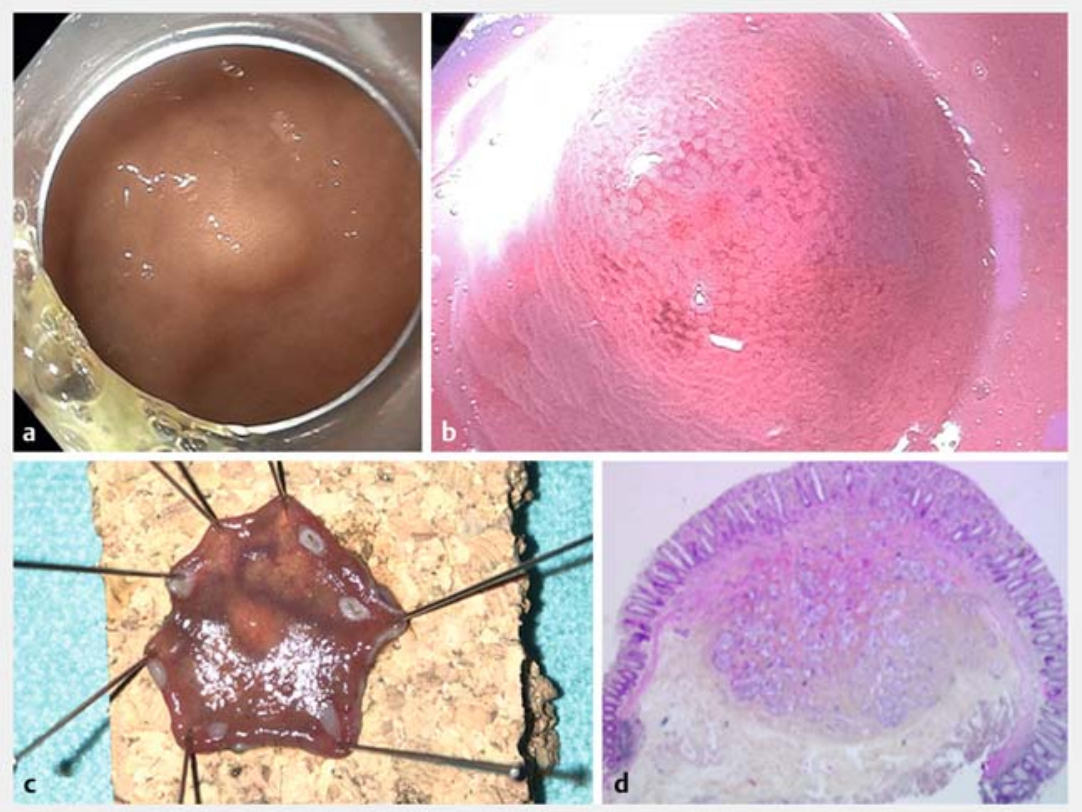

- Fig. 1 Appearance of a benign rectal neuroendocrine tumor: a endoscopic view with whitelight imaging; b endoscopic view with virtual chromoendoscopy; c macroscopic appearance of the resected specimen; $\mathbf{d}$ histologic appearance showing a G1 submucosal tumor with R0 resection. 

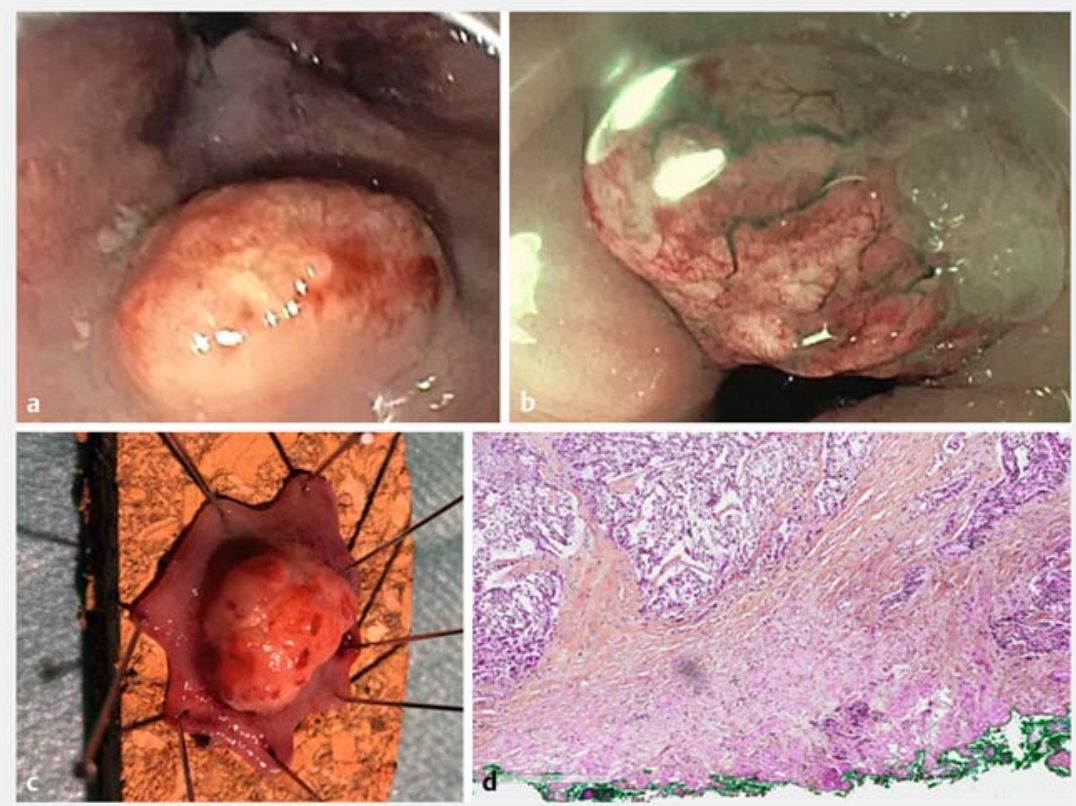

> Fig. 2 Appearance of a malignant rectal neuroendocrine tumor: a endoscopic view with white-light imaging; $\mathbf{b}$ endoscopic view with virtual chromoendoscopy; $\mathbf{c}$ macroscopic appearance of the resected specimen; $\mathbf{d}$ histologic appearance showing a $\mathrm{G} 2$ tumor with muscular and lymphovascular invasion (R1 deep margin).

demonstrated liver metastasis during further evaluation.

This case illustrates the importance of macroscopic analysis, giving the example of the differences in endoscopic appearance between non-invasive and invasive rNETs, along with the corresponding histologic features ( $\vee$ Video 1 ).

Endoscopy_UCTN_Code_CCL_1AD_2AC

\section{Competing interests}

The authors declare that they have no conflict of interest.

The authors

Florian Veyre', Thomas Lambin', Caroline Fine $^{2}$, Tanguy Fenouil ${ }^{3}$, Florian Rostain ${ }^{1}$, Thomas Walter ${ }^{2}$, Mathieu Pioche ${ }^{1}$

1 Department of Endoscopy and Gastroenterology, Pavillon L, Hôpital Edouard Herriot, Hospices Civils de Lyon, France
2 Department of Digestive Oncology, Pavillon E, Hôpital Edouard Herriot, Hospices Civils de Lyon, France

3 Department of Digestive Pathology, Groupement hospitalier Est, Hospices Civils de Lyon, France

\section{Corresponding author}

\section{Mathieu Pioche, MD}

Endoscopy unit - Digestive Disease department, Pavillon L - Hôpital Edouard Herriot, 69437 Lyon, France mathieu.pioche@chu-lyon.fr

\section{References}

[1] Fine C, Roquin G, Terrebonne E et al. Endoscopic management of 345 small rectal neuroendocrine tumours: A national study from the French group of endocrine tumours (GTE). United European Gastroenterol J 2019; 7: 1102-1112

[2] Choné A, Walter T, Rivory J et al. Gastric neuroendocrine tumors display deep invasive features, with amorphous pit and irreg- ular vascular pattern, using narrow-band imaging and magnification. Endoscopy 2018; 50: E199-E201

[3] Kudo S, Rubio CA, Teixeira CR et al. Pit pattern in colorectal neoplasia: endoscopic magnifying view. Endoscopy 2001; 33: $367-$ 373

[4] Uraoka T, Saito Y, Ikematsu H et al. Sano's capillary pattern classification for narrowband imaging of early colorectal lesions. Dig Endosc 2011; 23 (Suppl. 1): 112-115

\section{Bibliography}

Endoscopy 2021; 53: E215-E216

DOI 10.1055/a-1244-9526

ISSN 0013-726X

published online 11.9.2020

(c) 2020. Thieme. All rights reserved.

Georg Thieme Verlag KG, Rüdigerstraße 14,

70469 Stuttgart, Germany

\section{ENDOSCOPY E-VIDEOS}

https://eref.thieme.de/e-videos

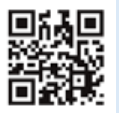

Endoscopy E-Videos is a free access online section, reporting on interesting cases and new

techniques in gastroenterological endoscopy. All papers include a high quality video and all contributions are freely accessible online.

This section has its own submission website at https://mc.manuscriptcentral.com/e-videos 